The Quarterly Journal of Austrian Economics

Volume 23 | NO.3-4 | 281-312 | Fall/Winter 2020 WWW.QJAE.ORG

\title{
Carl Menger's Grundsätze as a FOUNDATION FOR CONTEMPORARY ENTREPRENEURSHIP RESEARCH
}

\author{
RANDALl WeSTGREN ${ }^{*}$
}

JEL Classification: B53, L26

Aвstract: This paper takes the subjective value theory, conception of economic goods, and the hierarchy of needs from Carl Menger's Grundsätze der Volkswirtschaftslehre (1871) to elaborate a model of strategic entrepreneurship. Menger's account of subjective valuation by buyers of goods in market exchange fills a gap in most conceptual approaches to entrepreneurship, which are based on a highly impermeable boundary around the entrepreneurial firm. We examine how this account "closes" an economic model of entry for an entrepreneurial firm in an existing rivalry network by making the assessment of value explicit with respect to buyer needs relative to goods sold by incumbent firms. A formal representation of Menger's needs hierarchy in the face of qualitatively different market goods is the centerpiece of the strategic entrepreneurship model. This conceptual model is tied to methods of eliciting subjective valuations of product attributes and buyer needs fulfilment from the literatures of consumer behavior, marketing, and organizational psychology. This serves as a methodological basis for scholarship in entrepreneurship.

\footnotetext{
* Randall Westgren (westgrenr@missouri.edu) is professor of applied economics and the McQuinn Chair in Entrepreneurial Leadership at the University of Missouri-Columbia.
} 


\section{INTRODUCTION}

Scholars in the field of entrepreneurship flail about, seeking a theory that serves as a foundation for erecting boundaries to keep the field distinct from other territories in management and economics and to exploit as a basis for empirical analysis. In 2003, Scott Shane introduced a hubristic General Theory of Entrepreneurship, which attempted a link between the individualistic/personality-based accounts of David C. McClelland $(1965,1987)$ and a recently minted construct: the entrepreneurial opportunity. Since the publication of this tome, the field has maintained a vigorous discourse over the nature of the opportunity. It is beyond the scope of this paper to recount this history (readers interested in replowing the field can consult Short, Ketchen, Shook, and Ireland [2010]); however, for scholars of Austrian economics, it is interesting to note that one of the fault lines in the literature is the dichotomy between Kirznerian and Schumpeterian opportunities (Shane 2003, 21). Shane takes the idealtypus of Schumpeter's innovative, disequilibrating entrepreneur and Kirzner's metaphoric alert, equilibrating entrepreneur, reifies them into realtypus entrepreneurs, then rereifies them as social objects: opportunities. Thus, two Austrian accounts of market processes are bent into psychological types, thence into the creation opportunity and the discovery opportunity (Alvarez and Barney 2007, 2010). Schumpeter and Kirzner have lost their place on the marquee, but their accounts of market processes remain as misapplied social objects to which entrepreneurial action is directed.

Fortunately, some scholars in the entrepreneurship field have sought to apply the theories and constructs from Austrian economics in a more apropos manner. It must be understood that these current contributions to the field may overlap with the theory of the firm (Bylund 2015; Foss and Klein 2012), strategic management (Foss and Lyngsie 2014), and market processes (Bylund 2011). The boundary walls for entrepreneurship are not as important in the Austrian tradition as they are to the evolving field of entrepreneurship. These contributions draw from all the generations of the Austrian economics tradition (Salerno 2002) and take advantage of subjectivism, dynamics of market processes, and capital theory. Two recent reviews offer useful insights into both the breadth and depth of contributions to entrepreneurship from the Austrian tradition (Klein 
and Bylund 2014; Foss, Klein, and McCaffrey 2019). This paper takes these contributions as given and also seeks to add some specific insights by Carl Menger to theory-based entrepreneurship research.

This paper takes the subjective value theory, the conception of economic goods, and the hierarchy of needs from Carl Menger's Grundsätze der Volkswirtschaftslehre $(1871)^{1}$ to elaborate a model of strategic entrepreneurship. Menger's account of value and exchange in the economic system is much more complete than his explicit presentation of the entrepreneur. His careful model of the genetic-causal process that links the transformation of commodities and other economic goods (services of labor and capital, as well as transport and storage) from higher order goods to consumer goods with attendant time delays and uncertainty is as valid today to describe entrepreneurial value creation as it was in the middle of the nineteenth century. More importantly, Menger's explicit insistence on subjective valuation by buyers of the final consumption goods as the basis for exchange fills a gap in most accounts of entrepreneurship, which are based on a highly impermeable boundary around the entrepreneurial firm. Pricing of the entrepreneur's product is not generated within the opportunity or the firm, but is the result of a causal process of subjective assessment of the product's capacity to satisfy one or more of the buyer's wants.

The objective of this paper is to make this causal process explicit at the boundary of the entrepreneurial firm and the market (Bylund 2011). Following a brief review of Menger's conception of entrepreneurial action, we examine the substantive elements of Menger's ontology of economics that support valuation of entrepreneurial activity at the market divide between firms and buyers. To show the merits of Menger's theory to strategic entrepreneurship, a recent formal model of entrepreneurial entry is reviewed. The singular deficiency of that model is that buyer needs are elided. The deficiency is rectified by a combination of Menger's verbal

\footnotetext{
${ }^{1}$ I have endeavored to link the authoritative English translation by Dingwall and Hoselitz (Menger [1871] 2007) to the original German edition (Menger 1871). I use an electronic version of Grundsätze der Volkswirtschaftslehre that identifies the original pagination. For the translation, I use the 2007 version produced by the Ludwig von Mises Institute. Dingwall and Hoselitz moved some of Menger's original footnotes to the translated text; these discrepancies are noted where important, as are translated passages that appear to misinterpret Menger.
} 
representation of hierarchical needs and a formal model developed a century after his treatise was published. Together, these two representations of the genetic-causal process between entrepreneurial action and the market's subjective assessment of the product and competing goods complete the account of new entry into a market. In the spirit of economic ecumenicalism, the appropriateness of verbal and mathematical representations of this causal process is addressed to support Menger's contributions to entrepreneurial action 150 years on.

\section{MENGER'S ENTREPRENEUR AND ECONOMIC ONTOLOGY}

In the Grundsätze, Menger spends only about four paragraphs describing the entrepreneur (Unternehmer) and, more importantly, entrepreneurial activity (Unternehmerthätigkeit). Given that Menger's project is about human action, the functions performed by the entrepreneur are essential.

\footnotetext{
Entrepreneurial activity includes: (a) obtaining information about the economic situation; (b) economic calculation-all the various computations that must be made if a production process is to be efficient (provided that it is economic in other respects); (c) the act of will by which goods of higher order (or goods in general-under conditions of developed commerce, where any economic good can be exchanged for any other) are assigned to a particular production process; and finally (d) supervision of the execution of the production plan so that it may be carried through as economically as possible. (Menger [1871] 2007, 160)
}

Hébert and Link (2009) place Menger's entrepreneurial role in their historical categories of manager/superintendent (with Say, Mill, and Marshall) and decision-maker (with Cantillon, Marshall, Wieser, Walker, Keynes, Mises, Shackle, Cole, and Schultz). Correctly, Hébert and Link do not include Menger's entrepreneur in the roles of innovator, enterprise owner, capitalist, industrial leader, contractor, or arbitrageur. I quibble with the exclusion of "organizer and coordinator of economic resources" and of "employer of factors of production" for Menger's entrepreneur. It is clear from chapter 3 of the Grundsätze, that Menger traces value creation from higher order goods, including labor services and other services 
(e.g. shipping, warehousing). This appears to be more about value creation through the (economizing) use of factors of production and purchased inputs than simply managing and making decisions.

One of Hébert and Link's roles is highly problematic, both in general and in the specific case of Menger: "the person who assumes the risk associated with uncertainty (Cantillon, Thünen, Mangoldt, Mill, Hawley, Knight, Mises, Cole, Shackle)" (2009, 100). Muddying risk and uncertainty is a problem in general, especially when Knight takes such care to separate them. But in the case of Menger, it is more substantive. First consider this quote:

it will be evident that I cannot agree with Mangoldt, who designates "risk bearing" as the essential function of entrepreneurship in a production process, since this "risk" is only incidental and the chance of loss is counterbalanced by the chance of profit. (Menger [1871] 2007, 161).

Menger footnotes this disagreement based upon Mangoldt (1855). In the original, one finds "die 'Gefahr' doch nur etwas accidentielles ist" (Menger 1871, 138n). The risk is accidental, not incidental. Thus, it appears that Menger denies risk bearing, in the sense of aleatory probabilities of economic outcomes, as an entrepreneurial function. However, in section 4 of chapter 1, "Zeit-Irrthum" ("Time and Error"), Menger asserts that

The greater or less degree of certainty in predicting the quality and quantity of a product that men will have at their disposal due to their possession of the goods of higher order required for its production, depends upon the greater or less degree of completeness of their knowledge of the elements of the causal process of production, and upon the greater or less degree of control they can exercise over these elements. The degree of uncertainty in predicting both the quantity and quality of a product is determined by opposite relationships. Human uncertainty about the quantity and quality of the product (corresponding goods of first order) of the whole causal process is greater the larger the number of elements involved in any way in the production of consumption goods which we either do not understand or over which, even understanding them, we have no control-that is, the larger the number of elements that do not have goods-character.

This uncertainty is one of the most important factors in the economic uncertainty of men, and, as we shall see in what follows, is of the greatest practical significance in human economy. (Menger [1871] 2007, 71) 
This characterization of uncertainty looks close to that of Knight (1921).

\begin{abstract}
At the bottom of the uncertainty problem in economics is the forwardlooking character of the economic process itself. Goods are produced to satisfy wants; the production of goods requires time, and two elements of uncertainty are introduced, corresponding to two different kinds of foresight which must be exercised. First, the end of productive operations must be estimated from the beginning. It is notoriously impossible to tell accurately when entering upon productive activity what will be its results in physical terms, what (a) quantities and (b) qualities of goods will result from the expenditure of given resources. Second, the wants which the goods are to satisfy are also, of course, in the future to the same extent, and their prediction involves uncertainty in the same way. The producer, then, must estimate (1) the future demand which he is striving to satisfy and (2) the future results of his operations in attempting to satisfy that demand. (Knight 1921, 237-39)
\end{abstract}

The foundation of Menger's account is the time delay in transforming goods of higher order into goods "directed finally to the satisfaction of human needs" (Menger [1871] 2007, 67). This is his genetic-causal process, a series of time-stepped transformations of commodities (Waaren) into consumer goods (Gebrauchsgüter), in which the consumer values the economic character of the goods in the final exchange. Inside that valuation, there must be a payment for capital and for entrepreneurship.

The aggregate present value of all the complementary quantities of goods of higher order (that is, all the raw materials, labor services, services of land, machines, tools, etc.) necessary for the production of a good of lower or first order is equal to the prospective value of the product. But it is necessary to include in the sum not only the goods of higher order technically required for its production but also the services of capital and the activity of the entrepreneur. For these are as unavoidably necessary in every economic production of goods as the technical requisites already mentioned. Hence the present value of the technical factors of production by themselves is not equal to the full prospective value of the product, but always behaves in such a way that a margin for the value of the services of capital and entrepreneurial activity remains. (Menger [1871] 2007, 161)

Evidently, Menger dismisses aleatory risk as an element of entrepreneurship, as all economic agents face these accidental errors across 
time and space. But, if (a) the causal process that transforms higher order commodities into first order consumption goods is the essence of entrepreneurial activities and (b) those activities are fraught with epistemic uncertainty (a knowledge problem) and (c) valuation of consumption goods should include returns to entrepreneurial activity, then those returns must reflect returns to judgment in the face of uncertainty (Foss and Klein 2012). Thus, we can relate Menger's conception of entrepreneurial activity to contemporary accounts of entrepreneurship, particularly where decision-making and exercising judgment under uncertainty are central. However, it is paramount to understand that the Unternehmerthätigkeit that brings the consumer good to the market affords no guarantee that the returns to entrepreneurial activity will be positive; the essence of entrepreneurship is the economizing behavior in the face of uncertainty.

But there are other pieces of Menger's economic ontology that can contribute to the advancement of the economics of entrepreneurship. It seems that every economist that reads the Grundsätze finds something particularly insightful, but often lost from discourse in neoclassical economics (Hayek 1934; Stiglitz 1937; Georgescu-Roegen 1954; Schumpeter 1954). Both Hayek (1934) and Stiglitz (1937) point to a combination of the subjective valuation of consumer goods by buyers and the imputation of value backward through the higher orders of goods, including commodities and the services of human action-including labor and entrepreneurship, the critical departure from classical economics and conceptually superior to the contemporary accounts of Jevons and Walras. Menger is profoundly clear that he is concerned with all economic goods, including labor services and intangibles (Verhältnisse), as well as entrepreneurial action. These goods have goods-character (Güterqualität) $^{2}$ that is determined by no intrinsic valuation (e.g. labor value or physical costs of production), but by how the buyer values the good in exchange. Stiglitz is unique in proposing that this chain of valuation from consumer goods through all higher order goods follows the same pattern of uncertainty bearing in the economizing process of production that the final market valuation

\footnotetext{
${ }^{2}$ Dingwall and Hoselitz (Menger [1871] 2007, 52n3) explain that Menger uses both quality (Qualität) and character (Charakter) to describe the attributes of goods that respond to buyer needs. We return to this in a later section of the current paper.
} 
does. That is, the goods-character at any point in the chain has economic value derived from the subsequent goods-character of the later goods in the transformation process. We return to this important feature when we disaggregate goods-character explicitly into attributes in the next two sections of the paper.

The second innovation of Menger's ontology that affects the economics of entrepreneurship was masked by the characterization of utility in neoclassical economics. Georgescu-Rogen (1954) points to Menger's insistence that buyer valuation is tied to a multiplicity of wants or needs that are held in the consumer's mind in a hierarchy. Buyers seek to fulfill these wants by purchasing consumer goods such that higher-valued wants are met first and the marginal wants have been met at the same comparable degree when the budget for the period in question is exhausted by the marginal Gebrauchsgüter. Georgescu-Roegen makes the compelling case that neoclassical theory reduces the complex nature of individual wants, with varying intensities and inherent incommensurabilities, to a common want: utility. He argues that wants are irreducible. At the very least, "bread cannot save someone from dying of thirst,... living in a luxurious palace does not constitute a substitute for food, etc." (Georgescu-Roegen 1954, 514). As one of the foremost mathematical economists of the twentieth century, Georgescu-Roegen does not stop with this verbal assault on the false reduction of wants to utility; he shows that a hierarchical set of wants permits preference relations to exist between goods for rational choice, but that indifference between market baskets cannot be supported. Choices cannot be ordinally measurable. We return to the implications of this in a later section of the paper. First, we consider a recent economic model of entrepreneurship that will serve as a foil for incorporating Menger's insights.

\section{THE (NEARLY) NEOCLASSICAL ECONOMICS OF ENTREPRENEURSHIP}

In a recent article, Randall Westgren and Robert Wuebker (2019) present a formalized economic model of entrepreneurial entry into an existing industry/market. Their intent is to identify the portion of rent streams above contractible and noncontractible costs that can be attributed to entrepreneurial activity. Their model and consequent 
analysis turns on value creation - to encompass payments to capital, labor, purchased inputs, and the agent or agents that fulfill Menger's entrepreneurial role and other roles such as innovation and uncertainty-bearing - preceded by the creation of value for buyers in the marketplace. That is, Westgren and Wuebker follow Menger's ontology (without knowing) for imputation of value from the market between entrepreneurs and potential buyers. That is, the entrepreneur designs the new entry product to be qualitatively different from incumbent products or to have a cost structure that is superior for a qualitatively similar product, a microlevel expression of Michael E. Porter's (1980) differentiation and cost advantage strategies.

The Westgren and Wuebker (2019; hereafter WW) model makes differentiation and cost advantage explicit in the characteristics or attributes of the product, following Kelvin Lancaster's (1966, 1971) model of his "new approach" to consumer demand. Following Lancaster (1966), each product is characterized by a vector of attributes of interest to buyers, which create value. This is, effectively, a model of goods-character (Güterqualität) for consumer goods (Gebrauchsgüter).

(1) $X_{t}^{i}=G_{t}^{i}\left(z_{1}^{i}, z_{2}^{i}, \ldots, z_{j}^{i}, \ldots\right)$, or, in vector shorthand, $X_{t}^{i}=G_{t}^{i}\left(\vec{Z}_{t}^{i}\right)$, where $G_{t}^{i}$ is the quality function-the production outcome-that relates the individual attributes $z_{j}$ to product $i$. We expect the products $i$ and $j$ to be qualitatively distinct:

(2) $G_{t}^{i}\left(\vec{Z}_{t}^{i}\right) \neq G_{t}^{j}\left(\vec{Z}_{t}^{j}\right)$, where $z_{i} \in R^{n}$.

The quality bundles may differ by both which attributes $z_{i}$ appear in the product and how they are combined by the quality function. WW follow Lancaster's convention that a product consists of a linear combination of the attributes. The attributes and products that exist in the industry at time $t$ will be:

(3) $[Z]=[G][X]$

where the vector of product attributes $[Z]$ is related to the vector of $r$ goods [X] by a rectangular matrix of what are effectively inputoutput coefficients that "count up" the product attributes in each unit of each good produced by the $r$ members of the industry. At the limit, [G] is of dimension $r \times n$.

WW and Lancaster continue with the presumption that buyers assess attributes in characteristics space but express their preferences in goods space: 
(4) $[\mathbf{G}]=\left[\begin{array}{cccc}z_{1}^{1} & z_{2}^{1} & \ldots & z_{n}^{1} \\ z_{1}^{2} & z_{2}^{2} & \ldots & z_{n}^{2} \\ \vdots & \ddots & \ddots & \vdots \\ z_{1}^{r} & z_{2}^{r} & \ldots & z_{n}^{r}\end{array}\right] \quad[X]=\left[\begin{array}{c}X^{1} \\ X^{2} \\ \ddots \\ X^{r}\end{array}\right]$

where the subscripts denote the attributes $\{1,2,3, \ldots, n\}$ and the superscripts denote the products $\{1,2,3, \ldots, r\}$. The time period is suppressed for clarity, though it is imperative to remember that time figures greatly in analysis of innovation and new entrywhich follows directly from the foregoing analysis of Menger's production system.

The (time-suppressed) choice problem for each buyer is:

(5) $\operatorname{Max} U\left(z_{1}, z_{2}, \ldots, z_{m}\right)$

s.t.

(6) $P_{1} X_{1}+P_{2} X_{2}+\cdots+P_{r} X_{r} \leq B$

(7) $[Z]=[G][X]$ all $z_{i}, X_{j} \geq 0$.

In this general form, the utility obtained from characteristic $j$ may arise from it being solely available in a given good $X^{i}$ or it may come from several goods that express that characteristic in varying amounts. And any good may have several characteristics from the $n$ characteristics that appear in the utility function. This supports the analysis that WW present, whereby the combination of the relative amounts of each characteristic available from the $r$ goods is evaluated with the prices of the goods to obtain their shadow prices. This may be easier to evaluate in a two-dimensional characteristics space with four alternative goods. Figure 1 is based on both WW (2019) and Lancaster $(1971,39)$.

In figure 1 , each of the four goods comprises a unique ratio of $z_{2}$ to $z_{1}$ in each unit purchased. Good $X^{1}$ has the highest $z_{2} / z_{1}$ ratio per unit and good $X^{4}$ has the lowest. The points labeled 1, 2, 3, 4 are the points on the goods rays that exhaust the given budget allocation. The quantities of each good purchased may vary, but these points are analogous to the standard consumption frontier in neoclassical representations of the budget line in goods space. WW note that there are four stylized consumption points on this efficient 
frontier-labeled $A, B, C, D$-associated with four consumers (or consumer segments) who are "in the market for" $z_{1}$ and $z_{2}$. In Lancaster's terminology, consumer $\mathrm{A}$ and consumer $\mathrm{C}$ are vertex buyers: they exclusively buy, respectively, good 1 and good 3 . Because the $z_{2} / z_{1}$ ratios for the four goods do not maximize their respective utility functions, consumer $B$ buys some $X^{1}$ and some $X^{2}$ and consumer $\mathrm{D}$ splits purchases of $X^{3}$ and $X^{4}$. Lancaster calls these edge buyers. In three or more dimensions, there will be buyers who optimize as facet buyers, consuming multiple goods in higher dimensions of $z$ space.

\section{Figure 1. Four-Good, Two-Characteristic Choice Model}

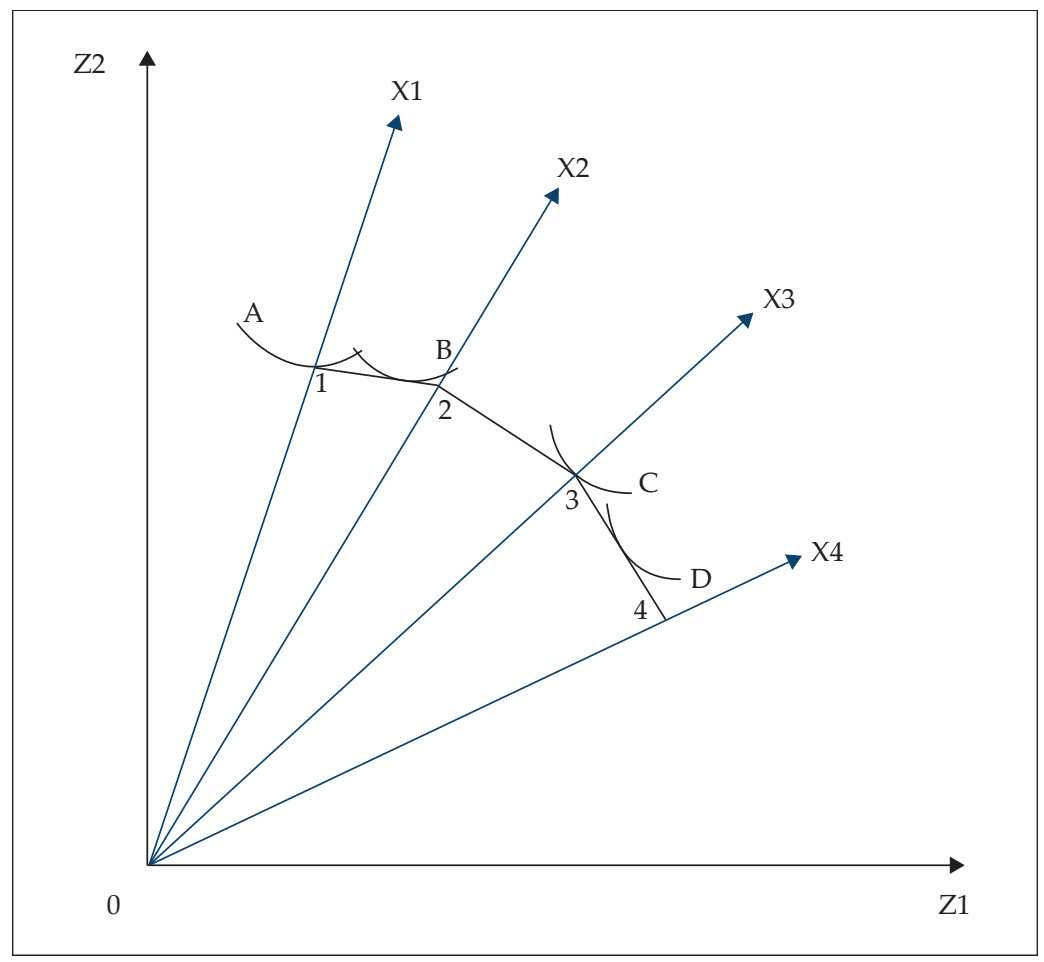

What happens when [G] is large? WW state that in the context of product innovation and entry, the number of strategically important characteristics will be small, following the logic of the 
resource-based strategy for the limited strategically important set of resources or factors of production (Barney 1986, 1991). Lancaster (1972) admits that the usefulness of his model is limited to instances where the number of operationally relevant characteristics is less than the number of goods. He proposes two ways to limit the dimensionality of [G]. The first way is technical. In any class of goods there will be a number of redundant characteristics or, perhaps, invariant characteristics across the class of goods. The nonredundant and highly variant characteristics will be a (small) subset of the $n$ possible arguments in $U$. Second, there will be human (goods-people) relations (Lancaster 1972). These include satiation (for one or more characteristics) and dominance, linked to the context of the purchase decision (e.g. hunger, low income). The technical algorithm is all about the structure of the $[G]$ matrix. Nearly all classes of potential buyers will eliminate irrelevant or common characteristics from consideration. Consider this representation of five (competing) products in a class of goods with seven measurable characteristics.

$$
[G]=\left[\begin{array}{ccccccc}
z_{1}{ }^{1} & z_{2}{ }^{1} & z_{3}{ }^{1} & z_{4}{ }^{1} & z_{5}{ }^{1} & 0 & z_{7}{ }^{1} \\
z_{1}{ }^{2} & z_{2}{ }^{2} & z_{3}{ }^{2} & z_{4}{ }^{2} & 0 & 0 & 0 \\
z_{1}{ }^{3} & z_{2}{ }^{3} & z_{3}{ }^{3} & z_{4}{ }^{3} & 0 & z_{6}{ }^{3} & z_{7}{ }^{3} \\
z_{1}{ }^{4} & z_{2}{ }^{4} & z_{3}{ }^{4} & z_{4}{ }^{4} & z_{5}{ }^{4} & z_{6}{ }^{4} & 0 \\
z_{1}{ }^{5} & z_{2}{ }^{5} & z_{3}{ }^{5} & z_{4}{ }^{5} & 0 & 0 & z_{7}{ }^{5}
\end{array}\right]
$$

Given the redundancy of characteristics $z_{1}-z_{4}$ (although the individual amounts of the characteristics may vary), a buyer will sort on characteristics $z_{5}-z_{7}$. And if a buyer finds no utility in characteristic 5, the subset of goods that will enter the consideration set (Mehta, Rajiv, and Srinivasan 2003; Shocker, Ben-Akiva, Boccara, and Nedungandi 1991) will be $X^{2}, X^{3}$, and $X^{5}$. Depending on the utility weights for the six relevant characteristics, it is possible that $X^{2}$ will be dominated by $X^{3}$ or $X^{5}$-depending on the buyer's relative utility for $z_{6}$ and $z_{7}$ and the quantities of each of the five valued characteristics in the two goods.

Westgren and Wuebker (2019) complete their argument for using the Lancaster model as the core of the search process that 
an entrepreneur follows to find a profitable entry point into the strategy space inhabited by incumbent firms. The search process and the subsequent innovation in product space create one form of Schumpeterian competitive move: product innovation, where a new attribute bundle will disrupt the value assessment by buyers. If the new entry is tied to process innovation, then a Schumpeterian "new combinations" entry will be profitable if there is significant cost advantage in producing the relevant (even if redundant) product attributes. WW go so far as to illustrate that at the limit, the product or process innovation may lead to Schumpeter's creative destruction.

\section{IMPROVING ON THE LANCASTER MODEL WITH MENGER}

In the previous section of the paper, we proposed that the WW model elaborates Menger's goods-character by using Lancaster's characteristics space to make clear the source of utility in the buyer decision. We examine this in detail and tie this to Georgescu-Rogen's (1954) argument against the reducibility of wants to utility - a fault of neoclassical consumer theory that Lancaster maintains in characteristics space.

To be sure, Menger considers the quality of goods in section $C$ of part 2 of his third chapter, "Einfluss der verschiedenen Qualität der Güter auf ihren Werth," ("Influence of the Different Quality of Goods on Their Value.") But the salient point of this discussion is that we cannot assess the value of qualitatively or quantitatively different goods-i.e., goods of differing quality-objectively. Individual buyers satisfy different needs and wants by consuming goods of different quality and the decision of choosing one particular good of a given quality rests in part on the "importance of needs that would remain unsatisfied" by the choice (Menger [1871] 2007, 143). Moreover, this is a matter of

the particular satisfaction that depends on a particular concrete good when a whole group of needs stands opposite goods whose various units are capable of satisfying these needs in qualitatively different ways.... If goods of one quality can be replaced by goods of another quality, though not with the same effectiveness, the value of a unit of the goods of superior quality is equal to the importance of the least important satisfaction that is provided for by the goods of superior quality minus 
a value measure that is greater (1) the smaller value of the goods of inferior quality by which the particular need can also be satisfied, and (2) the smaller difference to men between the importance of satisfying the particular need with the superior good and the importance of satisfying it with the inferior one. (Menger [1871] 2007, 144-45)

Thus, Menger anticipates the essence of Lancaster's characteristics approach as the basis for qualitatively different goods, but requires that the choice function include the two central features of his approach to the valuation of goods: (1) the subjective evaluation of the quality of goods must be based on how they fulfill a hierarchy of needs/wants, and (2) the analysis requires identification of the marginal need not satisfied by the choice set. Lancaster's human relations algorithm is a shallow simulacrum of Menger's valuation system. Lancaster allows for satiation and dominance to limit the size of the choice set but does not incorporate either of these constructs formally into his maximand or as additional constraints beyond the budget set (Lancaster 1972). In fact, he describes Menger's approach to hierarchy in the 1972 paper but dismisses it because "[h]ierarchy in goods does not necessarily represent an underlying hierarchy of wants" (Lancaster 1972). Effectively, he gets Menger's logic backwards. Any hierarchy of goods choice is, in fact, driven by the hierarchy of wants. Moreover, Lancaster highlights the importance of satiation to Menger.

Closely associated with the idea of a hierarchy of wants is some kind of satiation effect. In the original arguments of Menger and other writers in the same vein, the hierarchy was relevant because the consumer satisfied his wants in order of importance. Obviously, unless the most important want was satiable, the next most important would be irrelevant. (Lancaster, 1972, 59)

Clearly, Menger would agree with the last sentence if the circumstances of the buyer were limited and she could not command the necessary resources to fulfill the highest need. But this is trivial. All accounts of consumer choice theory require sufficiency of the budget constraint to purchase a minimal market basket to sustain life.

Lancaster hints at the salience of wants but does not include them in his utility function. All characteristics are evaluated on some common measure of utility and the compensatory nature of this 
utility function permits direct tradeoffs between all characteristics and, hence, the goods that comprise them. Lancaster requires that the utility function $U\left(z_{1}, z_{2}, \ldots, z_{m}\right)$ have the same properties of the neoclassical economics maximand for choice in goods space. It must be differentiable and the purchase of any good with low levels of any $z_{i}$ must able to be compensated by the choice of any other good that contributes more $z_{i}$ so as to maximize utility. That is, there are indifference curves in attribute space that behave the same way as indifference curves in goods space. As Georgescu-Roegen (1954) points out, is these qualities are incompatible with a hierarchy of wants and, moreover, reduces wants to a single-valued utility measure that effectively homogenizes them.

Can we improve on this by capturing more of Menger's account of hierarchical wants? That is, can we improve the formal model of Lancasterian choice to make the entrepreneurial action of WW more explicit? Yes. There is a significant piece of conceptual modeling that closes the gap between Menger and Lancaster. In 1972, Duncan Ironmonger published a book entitled New Commodities and Consumer Behaviour based on his $1961 \mathrm{PhD}$ dissertation completed at Cambridge University. Ironmonger was particularly interested in developing an approach to support empirical analysis of demand for new and qualitatively different goods.

\section{Choice under Priorities among Wants}

The Ironmonger model's formal symbols are very close to those of Lancaster (1966), save for the fact that $z_{i}$ is no longer the level of characteristic $i$, but the quantity of satisfaction of want $i$ (per unit of time). Furthermore, the system has the following variables (time suppressed):

$X^{j}$ is the number of units of good $j$ consumed per unit of time,

$z_{i}$ is the quantity of satisfaction of want $i$ per unit of time,

$w_{i} i$ is the quantity of satisfaction of want $i$ per unit of good $j$ consumed,

$P^{j}$ is the price per unit of good $j$, and

$Y$ is the income per unit of time.

There are three objectively measurable variables: $X^{j}, P^{j}$, and $Y$. There are two subjectively valued variables: $z_{i}$ and $w_{i}$. In matrix form, $[W]$ 
is the matrix showing how $\mathrm{m}$ wants are satisfied by $n$ goods, $p$ is a vector of length $n$ for prices, and $[X]$ is a vector of $n$ goods.

If one were to define a compensatory utility function in the manner of neoclassical theory or in Lancaster's model, it would appear as

(9) $U=U\left(z_{1}, z_{2}, \ldots z_{n}\right)$.

Ironmonger wishes to represent want satisfaction as a hierarchical (lexicographic) utility function. For two specific wants, $z_{1}$ and $z_{2}$ where $z_{1}$ has priority over $z_{2}$, there is no longer a continuous single utility function.

(10) $U=U_{1}\left(z_{1}\right)$, where $0 \leq z_{1}<z_{1}^{*}$ and $z_{2} \geq 0$, with $\delta U_{1} / \delta z_{1}>0$ and $U=U_{1}\left(z_{1}^{*}\right)+U_{2}\left(z_{2}\right)$ where $z_{1} \geq z_{1}^{*}$ and $z_{2} \geq 0, \delta U_{2} / \delta z_{2}>0$.

This is a two-step utility function, where below a satiation point $z_{1}{ }^{*}$ for the higher priority want, utility is measured entirely by the satisfaction level for $z_{1}$ even if the consumption set (not yet defined) yields some positive satisfaction of the second want. After satiation of the priority want, utility is only increasing for the satisfaction of the second want even if more $z_{1}$ occurs. In a world of three or more wants, the level of utility increases only with the marginal increase in the utility of the lowest want that is not yet satisfied by satiation. This is perfectly coherent with chapter 3 of Menger (1871).

Ironmonger presents a mathematical treatment of a system with $m$ wants and $n$ goods. He also allows any good to satisfy more than one want and there can be more than one good that satisfies any particular want. This echoes Menger in his section on the original measure of value.

\footnotetext{
But in ordinary life the relationship between available goods and our needs is generally much more complicated. Usually not a single good but a quantity of goods stands opposite not a single concrete need but a complex of such needs. Sometimes a larger and sometimes a smaller number of satisfactions, of very different degrees of importance, depends on our command of a given quantity of goods, and each one of the goods has the ability to produce these satisfactions differing so greatly in importance. (Menger [1871] 2007, 129)
}

Both Menger and Ironmonger agree on what they call the economizing and maximizing behavior, respectively. The consumer chooses goods such that the largest number of wants can be satisfied, given that all the wants that are more important than the 
least important satisfied want are likewise satisfied (at the level of satiation). The hierarchy of wants matters. The failure to satiate any higher-level want cannot be compensated by satiation of any number of lower-level wants. Menger illustrates this with a verbal account of finding the marginal want (that is not satiated). Ironmonger formalizes this as a linear programming model where the $i$ th want is not satiated; it is the marginal want.

As the consumer has priorities among his wants, he ranks the boundary planes $^{3}$ in order of his priorities, and then he satiates the ith want if he can satiate at the same time all wants prior to the ith. The consumer will [original emphasis] satiate his ith want if there exists a point $\bar{X}$ in the commodity space that satisfies the set of $i+1$ inequalities $p^{\prime} \bar{X} \leq y$ and $W_{i} \bar{X} \geq z_{i}^{*}$ where $W_{i}$ is the submatrix formed from the first i rows of $W$ and $z_{i}^{*}$ is the subvector formed from the first $i$ elements of $z^{*}$. If an $\bar{X}$ exists for the (i-1)th want but not for the ith, then the ith want is the marginal want. The optimum budget is that budget which maximizes the satisfaction of the ith want. (Ironmonger 1972, 33)

We can effectively rewrite the WW model to commit to Menger's theory by combining elements of Ironmonger's model. Remember that $z_{k}$ is now the level of satisfaction of the $k$ th want and WW's [G] matrix of the yield of characteristic $k$ by the consumption of one unit of good $j$ is replaced by the Ironmonger $[\mathrm{W}]$ matrix, which depicts the satisfaction of want $k$ by the consumption of one unit of good $j$. And the maximand (utility function) has to identify the marginal want that is satisfied and the marginal want that remains unsatisfied. We will use Ironmonger's notation for the marginal unsatisfied want " $\mathrm{i}$ " and the last satisfied want " $\mathrm{i}-1$." Since Menger requires a strict hierarchical or lexicographic ordering between the highest level want $z_{1}$ and the lowest level expressed want $z_{n^{\prime}}$ there must exist a boundary between satiated wants and the highest (of remaining wants) that is not satisfied.

$\left(5^{\prime}\right) U=U\left(z_{1}, z_{2}, \ldots, z_{k}, \ldots, z_{i-1}, z_{i}, \ldots, z_{n}\right)$, where

$U=\sum U_{k}\left(z_{k}\right)$, where $0 \leq z_{k}<z_{k}^{*}$ with $\delta U_{k} / \delta z k>0$ and

for all $z_{k}<z_{i}$

\footnotetext{
${ }^{3}$ Boundary planes separate the set of wants into two regions: those wants that are satiated and those that are not. The linear programming model seeks to maximize the number of fully satiated wants at this boundary in want space.
} 


$$
\begin{aligned}
& U=\sum U\left(z_{i-1}^{*}\right)+U_{i}\left(z_{i}\right), \text { where } z k \geq z k^{*} \text { and } 0 \leq z_{i}<z_{i}^{*}, \\
& \delta U_{k} / \delta z_{k}=0 \text { and } \delta U_{i} / \delta z_{i}>0 .
\end{aligned}
$$

s.t.

(6) $P_{1} X_{1}+P_{2} X_{2}+\cdots+P_{r} X_{r} \leq B$

$\left(7^{\prime}\right)[Z]=[W][X]$

all $z_{i}, X_{j} \geq 0$.

The equations ( $\left.5^{\prime}\right),(6)$, and $\left(7^{\prime}\right)$ represent Menger's causal model for one consumer, given $r$ known goods $[\mathrm{X}]$ and their market prices $\left\{P_{1}, P_{2}, \ldots, P_{r}\right\}$. The $[W]$ matrix is the subjective evaluations by that consumer for the satisfaction obtained for each unit of the known goods consumed. The vector [Z] is also subjectively known by that consumer-the rank order of her wants-as are the satiation levels $z_{k}^{*}$. It is helpful to think of the linked want-by-want utility function as a series of constraints on overall utility maximization that hold the wants as distinct, noncompensatory, and ranked-the essence of Menger's account.

\section{Implications for Entrepreneurship Theory}

How, then, can this model be used prior to entry by an entrepreneurial firm? From the perspective of the incipient entrepreneur, the model explains how purchase decisions are made based on buyers' assessments of how goods in the market will fulfill their needs hierarchies. And though the model is individualistic-and not as Lancaster intended his model-it allows the behavior of the representative buyer to be repeated across a number of individuals, if the number of goods in the market of interest is relatively small and the relevant wants are also few, to identify target markets for the new entry. The fact that individuals faced with this choice problem must identify a needs hierarchy implies much for the entrepreneur. The rankings and how they are distributed among buyers in the target market provide a great deal of product design information, even if the subjective valuations in the $[\mathrm{W}]$ matrix are not known. To the extent that data on purchases of incumbent goods imply how buyers perceive the mix of product attributes that satisfy needs, the entrepreneur can use his judgment to identify underserved needs and his ability to design a product to serve those needs at a cost 
that matches buyers' willingness to pay (Rossi, McCollough, and Allenby 1996; Allenby, Arora, and Gunter 1998).

There is another connection between Menger and contemporary scholarship. There is a body of theoretical and empirical work on cognitive models of the interactions between firms and consumers across "the market divide" (Porac and Rosa 1996). Joseph Porac and José Antonio Rosa describe imperfect information exchange between sellers and buyers given that these are subjectively assessed, especially if the product category is new. The markets are "inherently equivocal" and the standard tools of analysis such as cross elasticities of demand do not exist (Porac and Rosa 1996, 367). Rosa, Porac, Jelena Runser-Spanjol, and Michael Saxon (1999) elaborate the not-quite-shared process at the point of entrepreneurial action-new product entry-and note that

\footnotetext{
attributes do not exist on their own either. They are derived inductively through observation and interaction with products. The use and observation of products are idiosyncratic and dependent on a person's vantage point and observational goals....Consumers and producers bring their product conceptual systems to bear on market interactions. They use their conceptual systems to enact meaning for the physical artifacts they encounter and link the products to usage conditions and production or profit concerns. (Rosa et al. 1999, 67)
}

Eventually, the individuated product assessments become the basis for shared comprehension of the product attributes and how they satisfy buyer needs. This would correspond to the target market or market segments discussed above. But this market process is clearly consistent with Menger's subjectivism and his insistence that the array of individual valuations is not translatable into a single, stable market price.

\section{Noncompensatory Decision Theory and Marketing Research}

We are at a juncture that permits the application of market research methods to assess subjective variables inherent in the model shown above. These techniques of eliciting and analyzing data will lead to useful judgments about needs hierarchies, patterns of subjective beliefs held by active and latent buyers, and buyers' willingness to pay for attribute bundles that satisfy their needs, even for products 
that are still not on the market. Moreover, significant work was done from the 1980s through the 2000s on modeling consumer choice across product attributes using noncompensatory models (Johnson and Meyer 1984; Gilbride and Allenby 2004; Hauser 2009; Shin and Ferguson 2017). This research developed significant empirical evidence that consumers do not follow a decision process that implies a compensatory utility function. Many different noncompensatory choice models are supported by experimental results, including the hierarchical/lexicographic model embodied in equation (5') above. Others include a conjunctive decision rule, where some minimal level of all relevant attributes (i.e., need-satisfying product characteristics) must be present for the product to remain in the consideration set, and the disjunctive rule, where only the attribute(s) that satisfies the highest need causes the product to be considered.

It is possible now to take pairwise discrete choice data from controlled experiments and impute the choice model used by the subject. Repeating the experiment permits the researcher (or entrepreneur!) to build a simulation of perceived need fulfilment that can be used to simulate new product entry under alternative attribute designs (Train 2009). The complexity implied by the utility function in $\left(5^{\prime}\right)$ is easily handled by these methods, which were unavailable to Ironmonger in his subsequent empirical analyses of new product introductions in English (Ironmonger 1972) and Australian (Ironmonger, Lloyd-Smith, and Soupourmas 2000) households.

It is also possible through surveys of purchase intentions and controlled choiceexperiments to "extract" the subjective assessments from active and latent buyers' minds. These assessments include hierarchical preferences (or needs) and the strength of those preferences, willingness to pay for new product attribute bundles, and confidence in subjective assessments of alternative products. These are the data that permit the expression of Menger's model of buyer choice in a manner that completes the analysis of entrepreneurial action in the face of subjective valuation in the market. Such data will provide an improvement in the assessment of entrepreneurial entry over the model of Westgren and Wuebker, since their model seeks data on product attributes, not on how these attributes fulfill buyer needs. This Mengerian insight solves part of the epistemic uncertainty facing the Knightian entrepreneur as she develops her conjectures about expected market outcomes after entry. 


\section{FORMAL MODELS AND ENTREPRENEURIAL ACTION: A DISCUSSION}

In an oft-cited article, William Baumol (1968) argues that entrepreneurial action has been necessarily left out of formal neoclassical economics models. "The theoretical firm is entrepreneurless-the Prince of Denmark has been expunged from the discussion of Hamlet." (p. 66) This quote will elicit wry smiles from entrepreneurship scholars and economists that abjure formal models. Baumol, at least at this point in his writing, believes the neoclassical model cannot be augmented or altered in any meaningful way and that advances in modeling entrepreneurship lie in heterodox economics and psychology. He ignores prior economic analyses, notably from the Austrian school, that keep the Prince on stage save for two footnotes. One is a sop to Schumpeter (p. 70) and the other, surprisingly, to Veblen (Baumol 1968, 67). ${ }^{4}$

Veblen's 1898 polemic deserves some attention in two respects. First, in the article he acknowledges positively Menger and the Austrians' approach in developing subjectivism, but he is disappointed that they did not create an evolutionary account with cumulative causation. "[T]he later Austrian group struck out on a theory of process, but presently came to a full stop because the process about which they busied themselves was not, in their apprehension of it, a cumulative or unfolding sequence" (Veblen 1898, 386). This is clearly a failure by Veblen to understand Menger, BöhmBawerk, and Wieser. Perhaps he would have seen more clearly the genetic-causal tradition at the core of Austrian economics had he lived to see the term codified by Hans Mayer in the 1930s (Cowan and Rizzo 1996). In any case, Veblen's appreciation of Menger's subjective value theory and hierarchical needs is clear from his The Theory of the Leisure Class (1899).

\footnotetext{
${ }^{4}$ Baumol quotes Veblen's 1898 "Why Is Economics Not an Evolutionary Science?" The quote also appears in later books and anthologies. Veblen's polemic on (classical and neoclassical) economic man begins, "The hedonistic conception of man is that of a lightning calculator of pleasures and pains, who oscillates like a homogeneous globule of desire of happiness under the impulse of stimuli that shift him about the area, but leave him intact. He has neither antecedent nor consequent. He is an isolated, definitive human datum, in stable equilibrium except for the buffets of the impinging forces that displace him in one direction or another" (Veblen 1898, 389).
} 
The second point is that Veblen was speaking of the consumer and not the producing agent-entrepreneur or manager. Veblen's quotation repudiates the mechanistic utility maximization of the Lausanne school and its implied capacity for calculating across large sets of market goods. Veblen's socially stratified, socially embedded consumer behaves more akin to Menger's need satisfier. Veblen's cynicism aside, this is consistent with the model presented above that forms the basis for target markets (i.e., buyer segments) for the entrepreneur. But it is not about the missing Prince.

In this paper, we rely on formal models written with mathematical notation, rather than on verbal reasoning alone. In part, this serves to link the formal models of Westgren and Wuebker (2019), Lancaster (1966, 1971), and Ironmonger (1972) to the reasoning of Menger. I rely on the erudition of Salerno (2010) and his presentation of the praxeological method that links Menger to Rothbard (2009). Salerno notes the effective use of fictive or abstract constructs "that permit the economist to strip away all but the conditions of action that are essential to his analysis of cause and effect" (Salerno 2010, 8). The formal models exploited above do the same thing. Both the verbal account and the formal model are representations of economic phenomena (Hacking 1983). All representations of target (real) phenomena are false with respect to the target, regardless of whether they are verbal, graphical, or mathematical representations. Stripping away inessential elements of an economic phenomenon to core causal relationships gives us Menger's (1871, ch. 3) farmer with more grain than his household consumption needs require, Böhm-Bawerk's (1959) horse-wheat market, Lancaster's utility function for product attributes, and the demand curve we depict for university freshmen.

The value of representations is the stuff of philosophy of science. Cowan and Rizzo (1996) bring this to the fore in discussing the genetic-causal tradition in Austrian economics. They cite Nancy Cartwright (1983) and Uskali Mäki (1990, 1993) as defenders of this tradition as realism, despite the use of representations rather than full-blown accounts of the target (real) phenomenon. Cartwright $(1999,2007)$ carries this idea forward by suggesting that a representation is useful if it allows inferences about the target phenomenon. Mäki $(2009,2011)$ makes the case for models as representations of target systems if the isolations produce credible surrogates for the 
causal structure(s) of interest. He goes so far as to support "false" models: "I accept the weaker idea that a model may be true despite false assumptions. I also accept-and argue for in this paper-the stronger idea that a model may help capture truths thanks to false assumptions" (Mäki 2011, 48, italics original). It is informative for economists that Mäki chooses a piece by Menger's (near) contemporary, Johann Heinrich von Thünen, as a way to highlight the value of an isolated representation-the well-known Der isolierte Staat (The isolated state). Thünen double dips in isolation; he presumes that an isolated region exists in space and he isolates the economic functions of interest by assuming a flat, perfect, cultivatable plain and by assuming away topographic features that would confound transport costs. Mäki notes that this representation of economic geography has no resemblance to the target world but that the idealized model makes use of the fictions of which it is built to posit truths about economic behavior and its causal nature in the target world.

There is one additional distinction about models as representations that merits discussion. One can isolate the causal structure of interest by abstraction or by idealization. These two terms are not synonymous, but the boundaries between them may be fuzzy in practice. Levy (2018) drives a wedge between the terms by defining abstraction as omission of (true)elements of the target phenomenon in creating the representation-omission without misrepresentationand idealization as deliberate misrepresentation of the target-an "anti-factive" or "fictive" model. One would certainly characterize the axioms of rationality that undergird neoclassical models of consumer choice as idealization without even a whiff of abstraction. So, too, is Menger's analysis of consumption decisions based upon satisfying a known hierarchy of needs given a subjective evaluation of value of the goods-quality (Güterqualität). The causal nature of the representation derives from careful logical construction of the system of exchange across all manner of economic goods (Salerno, 1999). The "realist" half of the causal-realist approach of Menger is not based on abstraction, but on development of idealizations that hold across all of the transactions traced from higher-order goods to consumer goods. One may contrast this with an obvious abstraction process such as case studies or the German historical school, in which detail is omitted from the target world (context) to highlight some observed phenomenon. 
There are two important implications of training the lens of philosophy of science on both the Mengerian verbal causal-realist method and the models of Lancaster and Ironmonger. First, it is not true that an abstract model is more generalizable to the target world than an idealized model just because the former has some observable (factive) elements (Mäki 2009, 2011; Levy 2018). How closely a model resembles a target at some point in time does not imply its value as a representation of the target. Mäki emphases that the truth of the model lies not in resemblance, i.e., the truth of models, but in the truth in models whose construction (however fictive) yields inferences about causal mechanisms in the world (Cartwright 2007). This is Menger's design in the Grundsätze. The second implication is that there is no reason to prefer one representation over another unless it yields superior inferences about the phenomenon being modeled for a particular purpose for a specific audience (Mäki, 2011). That is, a mathematical representation may not be inferior to a verbal representation (e.g. Ironmonger vs. Menger) depending on the pragmatics of the purpose (e.g. building a computer model for empirical analyses vs. explication of the principles of economic behaviors) for two distinct audiences. To the extent that both Ironmonger and Menger capture the cause-effect relationships between need hierarchy and consumption choices among available goods, they are equivalent representations. To the extent that Ironmonger's model incorporates the logic of Menger's hierarchy of needs in a representation of consumption choice that is superior to Lancaster's model for the purpose of analyzing new entrants into product categories for entrepreneurship scholars, it is superior for that purpose.

\section{CONCLUSIONS}

The intent of this paper has been to illustrate that Menger's need hierarchy can be incorporated into a formal model of strategic entrepreneurship, such as that of Westgren and Wuebker (2019) so as to improve the representation of the choice behavior of buyers in target markets. This improved representation implies that an idealized model of entrepreneurial entry into a market whose customers are served (however well) by existing products can be more explicit. Moreover, by maintaining the distinctiveness (irreducibility) of 
wants that is the centerpiece of Menger's consumer theory, we have a clear theoretic foundation for value creation for the buyer that is missing from current conceptions of the economics of entrepreneurship. What then follows is a superior basis for imputing value to entrepreneurial action by new firms to take new products and/ or processes to the market. That is, we have a theoretical structure whereby the subjective valuation of the attributes of new products by buyers, according to their subjectively held wants, can be imputed to the combination of resources and inputs used by the entrepreneur.

Menger's ontology provides further insights, as his foundational consideration of the economic value of goods must include "a margin for the value of the services of capital and entrepreneurial activity" (Menger [1871] 2007, 161). Thus, the value of Schumpeterian innovation and Knightian (and Mengerian!) uncertainty bearing as entrepreneurial functions can be calculated over and above the production and transaction costs incurred by the firm (cf. Westgren and Wuebker 2019). Moreover, Menger requires that the economic value of intangible goods of higher order, such as intellectual property (patents, copyrights, brand names, etc.) — his Verhältnissebe included in the imputation. This means that the "teardown" cost estimates for consumer electronics are nonsense. They exclude the economic value of past entrepreneurial action in the creation of intangible resources that may create value in the buyers' of these products. Finally, the entrepreneurial actions that may be included in the third of Westgren and Wuebker's entrepreneurial functionsCoasean organization, which includes cost-saving business model innovations - can clearly be considered within the Verhältnisse. To the extent that these innovations create value for the buyer because of lower cost relative to subjective value, they fall under Menger's conception of entrepreneurship, i.e., economizing.

Where does this account of the economics of entrepreneurship fit with regard to the literature on entrepreneurial opportunity? It is superior to the so-called Kirznerian (objective) discovery opportunity (Shane and Venkataraman 2000). A Mengerian model of entrepreneurship cannot be considered as some exploitation of an objective opportunity that exists in the business environment, the metaphorical twenty-dollar bill lying on the sidewalk. The connection between entrepreneurial judgment and individual buyers' subjective evaluation of products is hardly exploitation of 
an objective social phenomenon. Ontologically objective opportunity has been debunked by McBride and Wuebker (2020), and the very essence of Austrian economics, which is reflected in this paper, supports subjectivism. Then, does this account add anything to the Schumpeterian creation opportunity (Alvarez and Barney 2007)? If the creative opportunity is conceived as wholly the result of cognitive processes and action interior to the firm, then it fails to link buyer valuation to value creation, at least explicitly. The creation opportunity, typically conceived as a social construction process by the entrepreneurial team, has nothing to support imputation of value in a meaningful way. This will lead inevitably to the problem of whether there are observable outcomes (i.e., profits) from this mind-dependent phenomenon (McBride and Wuebker 2020). The Austrian economic tradition requires human action in the sense of investments, market entry, and purchases by buyers which are, at best, only implied by a social constructionist account.

The economic model presented in this paper can be tested empirically by observing these human actions. Pragmatically, this will follow the marketing and organizational theory designs discussed above. Given the differences among need hierarchies in submarkets, how will putative target markets assess at the group level the subjective valuations of the attribute bundles? In one target market, a particular attribute will fulfill the highest-ranked need and in another target market, that need will be lower ranked. The market process allocates different attribute portfolios (i.e., goods) among buyers in the market. A necessarily concise list of needs and a necessarily limited set of product attributes will cause the emergence of submarkets with different, but commonly held need hierarchies which translate into market shares for the competing goods. These appear as the vertices and edges of the consumption space in Figure 1, as depicted in Westgren and Wuebker (2019). The hierarchy of needs is a missing element in the model that WW build from the Lancaster $(1966,1971)$ approach that permits compensatory utility assessments for buyers. When a noncompensatory utility function, such as a needs hierarchy, is imposed, the vertices (i.e., product loyalty) become more logical and better defined. This makes the entrepreneurial action of product design clear. It should improve WW's analysis of (product) innovation rents; product design responds to the entrepreneur's subjective assessment of the 
unmet needs in some target markets. Moreover, this is clearly the exercise of entrepreneurial judgment (Foss and Klein 2012) that is central to the value-generating activities of both Menger's and Knight's entrepreneur.

The connection between Menger and the work by Porac and Rosa on cognitive models of product and product category emergence admits the value of methodological individualism in a manner that is not widely echoed in the literatures of management, markets, and organizations. Methodological individualism has been a central tenet of Austrian economics from Menger onward. For clarity, one should devolve the term into two claims: ontological individualism and explanatory individualism (Epstein 2015). Ontological individualism is the claim that social facts are exhaustively determined by facts about individuals, their actions, and their interactions. Explanatory individualism is the claim that social facts are best explained by individuals' facts, actions, and interactions. Epstein cautions that both claims need to be examined on the merits of the theory and methodology being addressed (as opposed to all social science).

All of the explanatory power of this Mengerian approach to entrepreneurship is based upon individual choice. To the extent that some individuals can be aggregated into target markets according to their needs, this requires no additional assumptions of group-level characteristics or shared intentionality. Eventually, there will be social interactions among sellers and among buyers across the market divide, but the resultant social facts are additive of the individual social facts. Thus, this approach satisfies both ontological individualism and explanatory individualism.

In sum, we can argue that much of Carl Menger's unique ontology is preserved in our account of its value for entrepreneurship research. Although Menger's successors in the Austrian tradition took his groundbreaking treatise beyond its original scope, there are important lessons for the scholarship of entrepreneurship in the Grundsätze. In fact, one can see that much of Fritz Machlup's list of "the most typical requirements for a true adherent of the Austrian school" (Machlup 1981) are visible in our account: (1) methodological individualism, (2) methodological subjectivism, (3) tastes and preferences expressed as subjective evaluations of goods, (4) opportunity costs, and (5) marginalism. 
Beyond adherence to the traditions of Austrian economics, one hopes that this approach to the economics of entrepreneurship serves to advance contemporary thinking about the methodology of entrepreneurship research. By bringing buyer wants front and center, the calculation of entrepreneurial rents becomes less ad hoc and the design school approach can then be tied explicitly to imputation of value. And value creation is no longer about firm owners; it is about success in market entry.

\section{REFERENCES}

Allenby, Greg M., Neeraj Arora, and James L. Gunter. 1998. "On the Heterogeneity of Demand." Journal of Marketing Research 35: 384-89.

Alvarez, Sharon, and Jay B. Barney. 2007. "Discovery and Creation: Alternative Theories of Entrepreneurial Action." Strategic Entrepreneurship Journal 1: 11-26.

— . 2010. "Entrepreneurship and Epistemology: The Philosophical Underpinnings of the Study of Entrepreneurial Opportunities." Academy of Management Annals 4, no. 1: 557-83.

Barney, Jay B. 1986. "Strategic Factor Markets: Expectations, Luck, and Business Strategy." Management Science 32, no. 10: 1231-41.

_ 1991. "Firm Resources and Sustained Competitive Advantage." Journal of Management 17, no.1: 99-120.

Baumol, William. 1968. "Entrepreneurship in Economic Theory." American Economic Review 58, no. 2: 64-71.

Bylund, Per. 2011. "Division of Labor and the Firm: An Austrian Attempt at Explaining the Firm in the Market." Quarterly Journal of Austrian Economics 14, no. 2: 188-215.

- - 2015. The Problem of Production: A New Theory of the Firm. New York: Routledge.

Cartwright, Nancy. 1983. How the Laws of Physics Lie. Oxford: Oxford University Press.

— 1999. The Dappled World: A Study of the Boundaries of Science. Cambridge: Cambridge University Press. 
- 2007. Hunting Causes and Using Them: Approaches in Philosophy and Economics. New York: Cambridge University Press.

Cowan, Robin, and Mario J. Rizzo, 1996. "The Genetic-Causal Tradition and Modern Economic Theory." Kyklos, 49, no. 3: 273-317.

Epstein, Brian. 2015. The Ant Trap: Rebuilding the Foundations of the Social Sciences. New York: Oxford University Press.

Foss, Nicolai J., and Peter G. Klein. 2012. Organizing Entrepreneurial Judgment: A New Approach to the Firm. Cambridge: Cambridge University Press.

Foss, Nicolai J., Peter G. Klein, and Matthew McCaffrey. 2019. Austrian Perspectives on Entrepreneurship, Strategy, and Organization (Elements in Business Strategy). Cambridge: Cambridge University Press.

Foss, Nicolai J., and Jacob Lyngsie. 2014. "The Strategic Organization of the Entrepreneurial Established Firm." Strategic Organization 12, no.3: 208-15.

Georgescu-Roegen, Nicholas. 1954. "Choice, Expectations, and Measurability." Quarterly Journal of Economics, 47: 503-34.

Gilbride, Timothy J., and Greg M. Allenby. 2004. "A Choice Model with Conjunctive, Disjunctive, and Compensatory Screening Rules." Marketing Science 23, no. 3: 391-406.

Hacking, Ian. 1983. Representing and Intervening: Introductory Topics in the Philosophy of Natural Science. Cambridge: Cambridge University Press.

Hauser, J., 2009, "Non-Compensatory (and Compensatory) Models of Consideration-Set Decisions." Pp. 207-32 in vol. 14 of Proceedings of the Sawtooth Conference.

Hayek, Friedrich A. von. 1934. “Carl Menger.” Economica 1, no. 4: 393-420.

Hébert, Robert F., and Albert N. Link. 2009. A History of Entrepreneurship. New York: Routledge.

Ironmonger, Duncan. 1972. New Commodities and Consumer Behaviour. Cambridge: Cambridge University Press.

Ironmonger, Duncan, C. W. Lloyd-Smith, and F. Soupourmas. 2000. "New Products of the 80s and 90s: Diffusion of Household Technology in the Decade 1985-1995." Working paper, Department of Economics, University of Melbourne. 
Johnson, Eric J., and Robert J. Meyer. 1984. “Compensatory Choice Models of Noncompensatory Processes: The Effect of Varying Context." Journal of Consumer Research 11: 528-41.

Klein, Peter G. and Per L. Bylund. 2014. "The Place of Austrian Economics in Contemporary Entrepreneurship Research." Review of Austrian Economics 27, no. 3: 259-79.

Knight, Frank. 1921. Risk, Uncertainty, and Profit. New York: Houghton Mifflin.

Lancaster, Kelvin. 1966. "A New Approach to Consumer Theory." Journal of Political Economy 74: 132-56.

— . 1971. Consumer Demand: A New Approach. New York: Columbia University Press.

Levy, Arnon. 2018. "Idealization and Abstraction: Refining the Distinction." Synthese. https://doi.org/10.1007/s11229-018-1721-z.

Machlup, Fritz. 1981. "Homage to Mises." Pp. 19-27 in Homage to Mises: The First Hundred Years: Papers Delivered September 10 and 11, 1981, at Hillsdale College, Hillsdale, Michigan, for a Conference Commemorating the Centenary of the Birth of Ludwig von Mises (September 29, 1881-October 10, 1973), ed. John K. Andrews. Hillsdale, Mich.: Hillsdale College Press.

Mäki, Uskali. 1990. "Scientific Realism and Austrian Explanation." Review of Political Economy 2: 310-44.

—. 1993. "The Market as an Isolated Causal Process: A Metaphysical Ground for Realism." Pp. 35-59 in Austrian Economics: Tensions and New Developments, ed. Bruce Caldwell and Stephan Boehm. Boston: Kluwer.

—. 2009. "MISSing the World: Models as Isolations and Credible Surrogate Systems." Erkenntnis 70, no. 1: 29-43.

— . 2011. "Models and the Locus of Their Truth." Synthese 180, no. 1: 47-63.

McBride, Russ, and Robert Wuebker. Forthcoming "Social Objectivity and Entrepreneurial Opportunities." Academy of Management Review.

McClelland, David C. 1965. "N Achievement and Entrepreneurship: A Longitudinal Study." Journal of Personality and Social Psychology, 1: 389-92.

— . 1987. "Characteristics of Successful Entrepreneurs." Journal of Creative Behavior 21, no. 3: 219-33. 
Mehta, Nitin, Surendra Rajiv, and Kannan Srinivasan. 2003. “Price Uncertainty and Consumer Search: A Structural Model of Consideration Set Formation." Marketing Science 22, no. 1: 58-84.

Menger, Carl. 1871. Grundsätze der Volkswirtschaftslehre. Wien: Wilhelm Braumüller.

- . [1871] 2007. Principles of Economics. Trans. James Dingwall and Bert F. Hoselitz. Auburn, Ala.: Ludwig von Mises Institute.

Porac, Joseph, and José Antonio Rosa. 1996. "Rivalry, Industry Models, and the Cognitive Embeddedness of the Comparable Firm." Pp. 363-88 in vol. 13 of Advances in Strategic Management, ed. Joel A. C. Baum and Jane E. Dutton. JAI Press.

Porter, Michael E. 1980. Competitive Strategy: Techniques for Analyzing Industries and Competition. New York: Free Press.

Rosa, José Antonio, Joseph F. Porac, Jelena Runser-Spanjol, and Michael Saxon. 1999. "Sociocognitive Dynamics in a Product Market." Journal of Marketing 63: 64-77.

Rothbard, Murray N. 2009. Man, Economy, and State with Power and Market. 2d scholar's ed. Auburn, Ala.: Ludwig von Mises Institute.

Salerno, Joseph. 1999. "The Place of Mises's Human Action in the Development of Modern Economic Thought." Quarterly Journal of Austrian Economics 2, no. 1: 35-65.

— . 2002. "The Rebirth of Austrian Economics - in Light of Austrian Economics." Quarterly Journal of Austrian Economics 5, no. 4: 111-28.

— . 2010. "Menger's Causal-Realist Analysis in Modern Economics." Reviewof Austrian Economics 23: 1-16.

Schumpeter, Joseph A. 1954. History of Economic Analysis. Oxford: Oxford University Press.

Shane, Scott. 2003. A General Theory of Entrepreneurship: The Individual-Opportunity Nexus. Cheltenham, UK: Edward Elgar.

Shane, Scott, and S. Venkataraman. 2000. "The Promise of Entrepreneurship as a Field of Research." Academy of Management Review 25, no. 1: 217-26

Shin, Jaekwan, and Scott Ferguson. 2017. “Exploring Product Solution Differences Due to Choice Model Selection in the Presence of 
Noncompensatory Decisions with Conjunctive Screening Rules." Journal of Mechanical Design 139, no. 2.

Shocker, Allan, Moshe Ben-Akiva, Brunno Boccara, and Prakash Nedungandi. 1991. "Consideration Set Influences on Consumer Decision Making and Choice: Issues, Models, and Suggestions." Marketing Letters 2, no. 3: 181-97.

Short, J. C., D. J. Ketchen, C. L. Shook, and R. D. Ireland. 2010. “The Concept of Opportunity in Entrepreneurship Research; Past Accomplishments and Future Challenges." Journal of Management 36, no. 1: 40-65.

Stiglitz, George J. 1937. "The Economics of Carl Menger." Journal of Political Economy 45, no. 2: 229-50.

Thünen, Johann Heinrich von. [1821] 1910. Der isolierte Staat in Beziehung auf Landwirtschaft und Nationalökonomie. Jena, German Democratic Republic: Verlag von Gustav Fischer.

Train, K. E. 2009. Discrete Choice Methods with Simulation. 2d ed. Cambridge: Cambridge University Press.

Veblen, Thorstein. 1898. "Why Is Economics Not an Evolutionary Science?" Quarterly Journal of Economics 12, no. 4: 373-97.

Westgren, Randall, and Robert Wuebker. 2019. "An Economic Model of Strategic Entrepreneurship." Strategic Entrepreneurship Journal 13, no. 4: 507-28. 